\title{
Effect of Moderate Aerobic Exercise on Serum Levels of FGF21 and Fetuin $A$ in Women with Type 2 Diabetes
}

\section{Exir Vizvari}

Department of Exercise Physiology, Faculty of Humanities, Shams Institute of Higher Education, Gonbad Kavous, Iran. ORCID: 000000030760 4571

\section{Parvin Farzanegi}

(Phd)Department of Exercise Physiology, Faculty of Humanities, Sari Branch, Islamic Azad University, Sari, Iran

Hajar Abbas Zade

(Phd)Department of Exercise Physiology, Faculty of Humanities, Sari Branch, Islamic Azad University, Sari, Iran

Corresponding author: Exir Vizvari Email: vizvariexir@yahoo.com

Tel: +989112756903

Address: Department of Exercise Physiology,

Faculty of Humanities, Shams Institute of Higher

Education, Gonbad Kavous, Iran

Received: $2019 / 07 / 6$

Revised: 2019/08/17

Accepted: 2019/08/18

\section{(c) (i) (9)}

This work is licensed under a Creative Commons Attribution 4.0 License.

DOI: $10.29252 / \mathrm{mlj} .14 .6 .17$

\begin{abstract}
Background and objectives: Fibroblast growth factor 21 (FGF21) and fetuin $A$ are thought to be involved in the pathogenesis of metabolic disorders, such as type 2 diabetes. On the other hand, regular physical activity has an important role in the prevention and management of type 2 diabetes. The purpose of this study was to investigate effect of moderate aerobic exercise on serum levels of FGF21 and fetuin $A$ in women with type 2 diabetes.
\end{abstract}

Methods: This was a semi-experimental study with a pretestposttest design. The study was performed on 28 women with type 2 diabetes aged 40-50 years (mean weight: $70.58 \pm 2.11$ ) who were randomly divided into an exercise group $(n=14)$ and a control group $(n=14)$. The training intervention consisted of eight weeks of moderate aerobic exercise at $60-70 \%$ of maximum heart rate, five times a week. Serum levels of FGF21, fetuin A and some metabolic parameters were evaluated before the first session and 48 hours after the last session. All statistical analyses were performed in SPSS (version 24) using repeated measures ANOVA and at significance of 0.05 .

Results: The eight-week aerobic training intervention caused a significant increase in FGF21 and insulin sensitivity as well as a significant decrease in fetuin $A$, fasting blood sugar and HbAlc $(\mathrm{P}=0.001)$.

Conclusion: As a complementary therapy, regular aerobic exercise can be beneficial for type 2 diabetes patients in improving some metabolic parameters as well as FGF21 and fetuin A levels.

Keywords: Diabetes Mellitus Type 2, FGF21, Fetuin A,

Exercise 


\section{INTRODUCTION}

Diabetes refers to a group of metabolic disorders characterized by hyperglycemia, resulting from insulin resistance, loss of insulin secretion or both. Considering the rising prevalence of diabetes worldwide, it is expected that the disease will remain as one of the main causes of mobility and mortality (1). Also, epidemiological evidence indicates that diabetes is an important risk factor for atherosclerosis, which is the leading cause of death in diabetic patients (2). One the other hand, one of the factors affecting the development of chronic diseases, such as type 2 diabetes, is lack of physical activity. Several proteins that are exclusively or predominantly secreted by the liver are now known to directly affect energy metabolism. These liver-derived proteins, known as hepatokines, have important roles in promoting insulin resistance or improving metabolic variables of type 2 diabetes (3). One of these proteins is the fibroblast growth factor ${ }_{21}\left(\mathrm{FGF}_{21}\right)$, which is mainly expressed in metabolic tissues such as the liver and muscles. Systemic induction of $\mathrm{FGF}_{21}$ prevents obesity and decreases hyperglycemia and insulin resistance (4).

Therefore, it can lead to weight loss, decreased triglyceride and low-density lipoprotein (LDL) levels and improved insulin sensitivity (5). Fetuin A plays a major pathogenic role in metabolic diseases. This $64-\mathrm{kDa}$ glycoprotein is elevated in obesity and related disorders, such as metabolic syndrome and type 2 diabetes. Fetuin A concentrations are strongly correlated with impaired insulin sensitivity and glucose intolerance as it directly inhibits the downstream phosphorylation events of the insulin signaling cascade and the translocation of the glucose transporter type 4 (GLUT4) in insulin target tissues. It also affects atherosclerosis in diabetic patients $(3,6)$.

Aerobic exercise involves repeated and continuous movement of large muscles (7). Activities such as walking, cycling, jogging and swimming rely primarily on aerobic energy-producing systems. Regular physical activity has many beneficial health effects, especially on the treatment of chronic diseases, such as diabetes (8-10). Various studies have been carried out to examine effects of training on $\mathrm{FGF}_{21}$. Cuevas-Ramos et al. reported an increase in serum levels of $\mathrm{FGF}_{21}$ following physical activity (11). In another study, eight weeks of endurance training did not affect serum level of $\mathrm{FGF}_{21}$ in obese men (12). On the other hand, Yang et al. reported a decrease in serum level of $\mathrm{FGF}_{21}$ after three months of physical activity in obese women (10). Yong et al. observed no significant change in the fetuin A level following three months of physical activity (13). Another study reported a reduction in serum level of fetuin $\mathrm{A}$ in obese, adult women and men following endurance training (14). Schultes et al. also demonstrated that six weeks of aerobic exercise does not significantly change the serum levels of fetuin A in obese women (15). The purpose of this study was to investigate effects of eight weeks of moderate aerobic exercise on serum levels of $\mathrm{FGF}_{21}$, fetuin $\mathrm{A}$ and some metabolic parameters in women with type 2 diabetes.

\section{MATERIALS AND METHODS}

This semi-experimental study (clinical trial registrationnumber: IRCT20171104037225N1) was carried out with a pretest and posttest design. The study population included 28 women with type 2 diabetes who were referred to a Diabetes Center in Gorgan, Iran. The study was approved by the ethics committee of Islamic Azad University, Sari Branch (approval code: IR.IAU.SARI.REC.1396.55). Inclusion criteria were age range of 40-50 years, fasting blood sugar of $>126 \mathrm{mg} / \mathrm{dl}$, having type 2 diabetes for at least three years and $\mathrm{HbAlc}$ of more than $6.5 \%$. Exclusion criteria included history of insulin injection, fasting blood sugar of $>300 \mathrm{mg} / \mathrm{dl}$, regular physical activity in the past six months and history of hepatic and chronic heart disease. The subjects were asked not to perform any other form of physical activity. Insulin sensitivity was calculated based on the following formula: QUICKI=1/ [log (fasting insulin $(\mu \mathrm{U} / \mathrm{ml}))+\log$ (fasting glucose $(\mathrm{mg} / \mathrm{dl}))]$.

Exercise intervention was designed based on the recommendations of the American Diabetes Association and consisted of five sessions of exercise per week at moderate intensity $(60-70 \%$ of maximum heart rate) for eight weeks $(8,16)$. Each training session included 10 minutes of warm up and five minutes of cool down. The exercise protocol included aerobic exercise training in forms of walking, jogging, marching, $\mathrm{V}$ step, shuffle, mambo chasse, step touch and combination of these exercises (Table 1). 
Table 1. Details of the eight-week training program

\begin{tabular}{ccccccc}
\hline Week & $\begin{array}{c}\text { Saturday } \\
(\mathbf{m i n})\end{array}$ & $\begin{array}{c}\text { Sunday } \\
(\mathbf{m i n})\end{array}$ & $\begin{array}{c}\text { Tuesday } \\
(\mathbf{m i n})\end{array}$ & $\begin{array}{c}\text { Wednesday } \\
(\mathbf{m i n})\end{array}$ & $\begin{array}{c}\text { Thursday } \\
(\mathbf{m i n})\end{array}$ & $\begin{array}{c}\text { Intensity } \\
\text { (maximum } \\
\text { heart rate) }\end{array}$ \\
\hline 1st & 30 & 31 & 32 & 33 & 34 & $60 \%$ \\
\hline 2nd & 35 & 36 & 37 & 38 & 39 & $60 \%$ \\
\hline 3rd & 40 & 41 & 42 & 43 & 44 & $60 \%$ \\
\hline 4th & 45 & 46 & 47 & 48 & 49 & $65 \%$ \\
\hline 5th & 50 & 51 & 52 & 53 & 54 & $65 \%$ \\
\hline 6th & 55 & 56 & 57 & 58 & 59 & $65 \%$ \\
\hline 7th & 60 & 60 & 60 & 60 & 60 & $70 \%$ \\
\hline 8th & 60 & 60 & 60 & 60 & 60 & $70 \%$ \\
\hline
\end{tabular}

Metabolic parameters and serum levels of $\mathrm{FGF}_{21}$ and fetuin $\mathrm{A}$ were evaluated before the first session and 48 hours after the last session. Fasting blood samples were taken between 8:00 and 10:00 AM. Serum levels of $\mathrm{FGF}_{21}$ and fetuin A were measured using commercial enzyme-linked immune sorbent assay kits (Bio Vendor, Germany) with sensitivity of $7 \mathrm{pg} / \mathrm{ml}$ and $0.104 \mathrm{ng} / \mathrm{ml}$, respectively. Metabolic parameters were measured using an auto analyzer.

Descriptive statistics including mean values and standard deviation were used to describe the data. The Kolmogorov-Smirnov test and Levene's test were applied to determine normality of data distribution and homogeneity of variances, respectively. Statistical analysis was performed using repeated measures ANOVA in SPSS software (Version 24) and at significance level of 0.05 .

\section{RESULTS}

At baseline, there was no significant difference between the control and exercise groups. Eight weeks of moderate aerobic exercise caused a significant increase in $\mathrm{FGF}_{21}$ $(\mathrm{P}=0.001)$ and insulin sensitivity $(\mathrm{P}=0.001)$. Moreover, there was a statistically significant decrease in serum levels of fetuin A $(\mathrm{P}=0.001)$, fasting blood sugar $(\mathrm{P}=0.001)$ and $\mathrm{HbA}_{1} \mathrm{c}$ following the exercise intervention $(\mathrm{P}=0.001)$ (Table 2, Figures 1 and 2).

Table 2. Comparison of metabolic parameters before and after the exercise intervention in woman with type 2 diabetes

\begin{tabular}{cccccc}
\hline Variable & Groups & Pre-test & Post-test & Within groups & Between groups \\
\hline Fasting blood sugar & Control & $165.14 \pm 11.82$ & $164.79 \pm 12.12$ & 0.778 & $0.001^{*}$ \\
$(\mathbf{m g} / \mathbf{d l})$ & Exercise & $164.20 \pm 10.62$ & $134.29 \pm 9.55$ & $0.001^{*}$ & $0.001^{*}$ \\
HbA1c $(\%)$ & Control & $7.94 \pm 0.52$ & $7.93 \pm 0.55$ & 0.363 & $0.001^{*}$ \\
& & & & & $0.001^{*}$ \\
& Exercise & $8.10 \pm 0.58$ & $6.88 \pm 0.68$ & 0.771 & $0.001^{*}$ \\
Insulin sensitivity & Control & $0.303 \pm 0.005$ & $0.303 \pm 0.004$ & & \\
$($ QUICKI) & Exercise & $0.303 \pm .003$ & $0.319 \pm 0.003$ & & \\
& & & & &
\end{tabular}

*Significant difference compared to the control group

$¥$ Significant difference compared to pre-test 


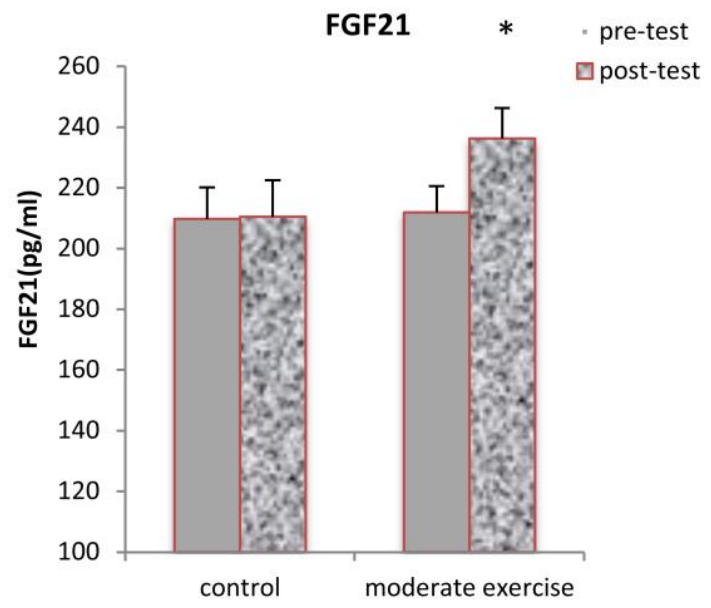

Figure 1. Effect of the training intervention on $\mathbf{F G F}_{21}$ levels. * indicates significant difference compared to the control group. $¥$ indicates significant difference compared to pre-test $(\mathbf{P}=\mathbf{0 . 0 0 1 )}$.

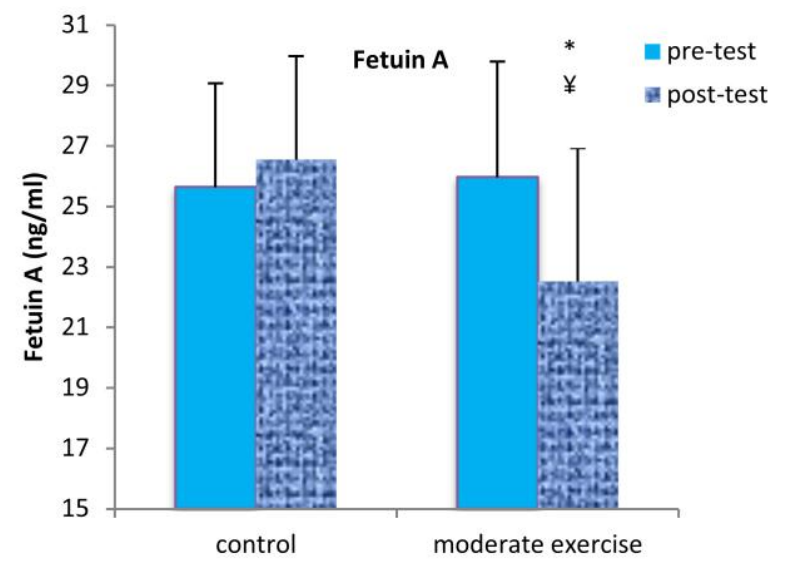

Figure. Effect of the training intervention on fetuin A levels. * indicates significant difference compared to the control group. $¥$ indicates significant difference compared to pre-test $(P=0.001)$. 


\section{DISCUSSION}

In this study, the effect of eight weeks of moderate aerobic exercise was evaluated on serum levels of $\mathrm{FGF}_{21}$ and fetuin $\mathrm{A}$ in women with type 2 diabetes. Based on the results, the exercise intervention caused a significant increase in $\mathrm{FGF}_{21}$ and insulin sensitivity and a decrease in fetuin A, fasting blood sugar and HbA1c. Regular physical activity controls blood glucose, fat and insulin resistance, which reduces the complications of diabetes. In accordance with these results, Vizvari et al. also observed a reduction in fasting blood sugar, $\mathrm{HbA} 1 \mathrm{c}$ and insulin resistance in diabetic patients following regular exercise (17). The improvement in insulin sensitivity could be due to the increased expression of GLUT4 and improved insulin signaling cascade. Moreover, $\mathrm{FGF}_{21}$ has been shown to decrease blood glucose levels by increasing GLUT 1 expression in human primary adipocytes (18). In the present study, the eight-week moderate aerobic exercise increased serum levels of $\mathrm{FGF}_{21}$, which is consistent with results of two previous studies $(19,20)$. However, a study reported that plasma level of $\mathrm{FGF}_{21}$ reduces after three weeks of training (21). The positive effects of regular physical activity on the metabolic parameters of diabetics may be exerted partly through mitochondrial biogenic proteins and glucose regulators, such as $\mathrm{FGF}_{21}$. Physical activity increases glucagon and free fatty acids release, which simultaneously increases the secretion of $\mathrm{FGF}_{21}$ from hepatocytes (22). In addition, $\mathrm{FGF}_{21}$ increases insulin-independent glucose uptake in adipose tissues (5) via expression of GLUT 1 and regulation of lipolysis (23). This protein also increases the mitochondrial oxidative capacity in adipose tissue, which is characterized by increased oxygen consumption and upregulation of key metabolic genes (24). In other tissues such as the liver and pancreas, $\mathrm{FGF}_{21}$ helps homeostasis (4). Increased phosphorylation of 5' AMP-activated protein kinase by $\mathrm{FGF}_{21}$ ultimately increases fat oxidation, glucose uptake and mitochondrial biogenesis $(25,26)$.

We also observed that the eight-week moderate aerobic training significantly reduced the serum levels of fetuin A. In line with this finding, Lee et al. reported $11 \%$ reduction in fetuin $\mathrm{A}$ after 12 weeks of training in middle aged men (27). Similarly, Salama and El-Damarawi demonstrated that regular exercise significantly decreases fetuin $\mathrm{A}$ in diabetic rats (28). On the other hand, observed study reported an increase in serum levels of fetuin $\mathrm{A}$ in men in response to six months of aerobic exercise (29). However, a study reported no significant change in fetuin A levels of non-diabetic obese women after six weeks of training (15). The inconsistency between the results could be attributed to differences in the exercise protocol, duration and intensity of exercise as well as factors, such as health of subject. Fetuin A inhibits insulin receptor tyrosine kinase activity in skeletal muscle and adipose tissue (30). It also stimulates cytokines expression and lipogenesis while reducing adiponectin, which may consequently lead to insulin resistance (29).

\section{CONCLUSION}

As a non-pharmacological therapy, physical activity may exert beneficial effects on some metabolic parameters in diabetics through improvement of serum $\mathrm{FGF}_{21}$ and fetuin $\mathrm{A}$ levels.

\section{ACKNOWLEDGEMENTS}

The authors are grateful to all study participants for their cooperation.

\section{CONFLICT OF INTEREST}

The authors declare that there is no conflict of interest.

\section{REFERENCES}

1- Ghane M. Investigation of Frequency of Herpes Simplex Virus in Patients with Type 2 Diabetes and Healthy Individuals by PCR and ELISA. Mljgoums. 2018; 12(1):6-10.

2- Vahedi M, Farzanegi P. The Effect of Portulacaoleracea $L$ Consumption and Regular Exercise on Levels of Cathepsin S, Cystatin $C$ And C-Reactive Protein in Diabetic Women. Mljgoums. 2015; 9(4): 47-53. DOI: 10.18869/acadpub.mlj.9.4.47.

3- Mook Choi K. The Impact of Organokines on Insulin Resistance, Inflammation and Atherosclerosis. Endocrinology and Metabolism. 2016; 31(1): 1-6. http://dx.doi.org/10.3803/EnM.2016.31.1.1

4- Oh KJ, Lee DS, Kim WK, Han BS, Lee SC, Bae K-H. Metabolic Adaptation in Obesity and Type II Diabetes: Myokines, Adipokines and Hepatokines. Int J Mol Sci. 2016; 18(1). pii: E8. doi: 10.3390/ijms18010008.

5-Jin Yoo H, Mook Choi Qu. Hepatokines as a Link between Obesity a Cardiovascular Diseases. Review. Diabetes Metab J. 2015; 39: 10-15. doi: 10.4093/dmj.2015.39.1.10.

6- Masanori Emoto M, Mori K, Lee E, Shoji T, Inaba M, Nishizawa Y. Fetuin-A and atherosclerotic calcified plaque in patients with type 2 diabetes mellitus. Metabolism. 2010; 59(6): 873-878.

7- Sigal R, Armstrong M, Colby P, Kenny G, Plotnikoff G, Reichert S, et al. Physical Activity and Diabetes. Can J Diabetes. 2013; 37: 40-44. OI:https://doi.org/10.1016/j.jcjd.2017.10.008.

8- Colberg Sh, Sigal R, Yardly J, Riddell M, dunstan D, Demosey $\mathrm{P}$, et al. Physical activity exercise and diabetes a position statement of the american diabetes association. Diabetes Care. 2016; 39(11): 2065-2079. doi: 10.2337/dc161728. 
9- Asle Mohammadi Zadeh M, Kargarfard M, Nazarali P. Comparison Of The Effects Of Interval Training With Different Diet On Il-6, Tnf-A And Some Of Metabolic Indexes In Obesity Type 2 Diabetic Men. ijdld. 2019; 18(3) :156-172.

10-Azali Alamdari K, Khalafi M. The effect of high intensity interval training on serum level of FGF21 and insulin resistance in obese men . ijdld. 2019; 18(1): 41-48.

11- Cuevas-Ramos D, Almeda-Valdés P, Meza-Arana CE, Brito-Córdova G, Gómez-Pérez FJ, Mehta R, et al. Exercise increases serum fibroblast growth factor 21 (FGF21) levels. PLos One. 2012; 7(5): e38022.

12-Besse-Patin A, Montastier E, Vinel C, Castan-Laurell I, Louche K, Dray C, et al. Effect of endurance training on skeletal muscle myokine expression in obese men: identification of apelin as a novel myokine. Int J obes (Land). 2014; 38(5): 70713.

13-Yang SJ, Hong HC, Choi HY, Yoo HJ, Cho GJ, Hwang TG, et al. Effects of a three-month combined exercise programme on fibroblast growth factor 21 and fetuin-A levels and arterial stiffness in obese women. Clin Endocrinol(oxf). 2011; 75(4): 464-9.doi: 10.1111/j.1365-2265.2011.04078.x.

14- Malin S, del Rincon J, Huang H, Kirwan JP. Exerciseinduced lowering of fetuin-A may increase hepatic insulin sensitivity. Med Sci Sports Exerc. 2014; 46: 2085-2090. doi: 10.1249/MSS.0000000000000338.

15- Schultes B, Frick J, Ernst B, Stefan N, Fritsche A. The effect of 6-weeks of aerobic exercise training on serum fetuin-A levels in non-diabetic obese women. Exp Clin Endocrinol Diabetes. 2010; 118(10): 754-756.

16- Vizvari E, Farzanegi P, Abbaszadesourati H. Effect of Moderate Aerobic Training on Serum Levels of Angiogenic and Angiostatic Factors in Women with Type 2 Diabetes. Sjimu. 2019; 27(1): 112-121.

17- Vizvari E, Farzanegi P, Abbas Zade Sourati H. Effect of Vigorous Aerobic Training on Serum Levels of Some Inhibitory and Excitatory Factors of Angiogenesis in Women with Type 2 Diabetes. Pathobiol Res. 2018; 21(3): 125-131.

18- Gimeno RE, Moller DE. FGF21-based pharmacotherapy: potential utility for metabolic disorders. Trends Endocrinol Metab. 2014; 25(6): 303-11.

19- Abbasi Daloii A, Maleki Delarestaghi A. The effect of Aerobic exercise on Fibroblast Growth Factor and Adiponectin in obese men. Journal of Sport Biosciences. 2017; 9(1): 109121.
20- Vizvari E, Farzanegi P, Abbas Zade Sourati H. Effect of Vigorous Aerobic Exercise on Serum Levels of SIRT,$F G F_{21}$ and Fetuin A in Women with Type II Diabetes. Mljgoum. 2018; 12(2):1-6. DOI: $10.29252 / \mathrm{mlj} .12 .2 .1$.

21- Scalzo R, Peltonen G, Giordano G, Binns S, Klochak A, Paris A, et al. Regulators of Human White Adipose Browning: Evidence for Sympathetic Control and Sexual Dimorphic Responses to Sprint Interval Training. PLoS One. 2014; 9(3): e90696.

22- Hansen JS, Pedersen BK, Xu G, Lehmann R, Weigert C, Plomgaard P. Exercise-Induced Secretion of FGF21 and Follistatin Are Blocked by Pancreatic Clamp and Impaired in Type 2 Diabetes. J Clin Endocrinol Metab. 2016; 101(7): 28162825. doi: 10.1210/jc.2016-1681.

23- Li Xia, Ge H, Weiszmann J, Hecht R, Li Y, Véniant M, Xu $\mathrm{J}, \mathrm{Wu} \mathrm{X}$, Lindberg $\mathrm{R}, \mathrm{Li} \mathrm{Y}$. Inhibition of lipolysis may contribute to the acute regulation of plasma FFAand glucose by FGF21 inob/ob mices. FEBS letters 2009; 583(19): 3230-3234

24- Zhu Sh, Ma L, Wu Y, Ye X, Zhang T, Zhang Q, Rasoul L, Liu Y, Guo M, Zhou B, Ren G and Li D. $F G F_{21}$ treatment ameliorates alcoholic fatty liver through activation of $A M P K-$ SIRT1 pathway. Acta Biochim Biophys Sin(ABBS) 2014; 46: 1041-1048.

25- Chau M, Gao J, Yang Q, Zhidan Wu, and Gromada J. Fibroblast growth factor 21 regulates energy metabolism by activating the AMPK-SIRT $T_{1}-P G C_{1} \alpha$ pathway. Proc Natl Acad Sci U S A. 2010; 107(28): 12553-12558. doi: 10.1073/pnas.1006962107.

26- Nara R, Scherolin O. Treadmill training increases $S I R T_{1}$ and $P G C_{l}$ a protein levels and $A M P K$ phosphorylation in quadriceps of middle-aged rats in an intensity-dependent manner. Mediators Inflamm 2014; 2014: 1-11.

27- Lee S, Norheim F, Gulseth H , Langleite M , Kolnes K, Tangen $\mathrm{D}$ et al. Interaction between plasma fetuin-A and free fatty acids predicts changes in insulin sensitivity in response to long-term exercise. Physiol Rep 2017; 5(5): e13183. doi: $10.14814 /$ phy2.13183.

28- Salama ME, El-Damarawi MA. Effect of two exercise varieties on fetuin-A plasma level in experimental diabetic nephropathy. Tanta Med J. 2017; 45(1): 21-28.

29- Blumenthal J, Gitterman A, Ryan A, Prio S. Effects of Exercise Training and Weight Loss on Plasma Fetuin-A Levels and Insulin Sensitivity in Overweight Older Men. J Diabetes Res. 2017; 2017:1492581.doi: 10.1155/2017/1492581.

30- Sun Q, Cornelis MC, Manson JE, Hu FB. Plasma levels of fetuin-A and hepatic enzymes and risk of type 2 diabetes in women in the U.S. Diabetes. 2013; 62(1): 49-55.doi: $10.2337 / \mathrm{db} 12-0372$

\section{How to Cite:}

Vizvari E, Abbas Zade H, Farzanegi P. [Effect of Moderate Aerobic Exercise on Serum Levels of FGF21 and Fetuin A in Women with Type 2 Diabetes]. mljgoums. 2020; 14(6): 17.22. DOI: 10.29252/mlj.14.6.17 